\title{
Density and Survival of Lady Beetles (Coccinellidae) in Overwintering Sites in Manitoba*
}

\author{
W. J. TURNOCK and I. L. WISE \\ Cereal Research Centre, Agriculture and Agri-Food Canada, 195 Dafoe Road, Winnipeg, Manitoba, Canada R3T 2M9
}

Turnock, W. J., and I. L. Wise. 2004. Density and survival of Lady Beetles (Coccinellidae) in overwintering sites in Manitoba. Canadian Field-Naturalist 118(3): 309-317.

The densities of lady beetles, Coccinellidae, overwintering as adults (adults per $\mathrm{m}^{2}$ ) in leaf litter collected in late October for two years in a beach-ridge forest on the south shore of Lake Manitoba were 56.4 for the Thirteen-spotted Lady Beetle, Hippodamia tredecimpunctata (Say), 38.3 for the Seven-spotted Lady Beetle, Coccinella septempunctata (L.), 7.7 for the Transverse Lady Beetle, Coccinella transversoguttata richardsonii Brown, 1.6 for the Convergent Lady Beetle, Hippodamia convergens Guerin, and 0.6 for the Parenthesis Lady Beetle, Hippodamia parenthesis (Say). The mean overwintering survival for these species was $0.254,0.036,0.023,0.0$, and 0.0 , respectively. The density of overwintering coccinellids was highest near the margins of the forest, particularly on the beach side, where beetles from shore appear to have entered the forest. The mean density over 3 years $\left(2.9\right.$ per $\left.\mathrm{m}^{2}\right)$ of all coccinellid species in November in the litter under a remnant grove of riverbank forest in Winnipeg, was lower than in the beach-ridge forest $\left(104.8\right.$ per $\left.\mathrm{m}^{2}\right)$, but their survival $(0.460)$ was higher than in the beach-ridge forest $(0.154)$. More species of coccinellids were found in the samples from the riverbank forest than from the beach-ridge forest.

Key Words: Lady Beetles, Coccinellidae, leaf litter, beach-ridge forest, overwintering sites, Lake Manitoba, Red River.

The overwintering sites of north-temperate zone coccinellids include leaf litter, grass tufts, bark crevices, stone piles, and rock clefts (Hodek and Honěk 1996). Adults of some species migrate long distances to hibernate at high elevations, and even those which move only locally seem to be attracted to even slightly higher elevations and vertical silhouettes. In Bohemia and Moravia, Coccinella septempunctata L. (C7) prefers elevated places, but also hibernates in refuges among cultivated areas and does not migrate long distances (Hodek 1960). In southern Manitoba, where much of the land is flat and cultivated, it is generally believed that lady beetles overwinter in the leaf litter under trees in field shelterbelts, farmsteads and urban plantings, along the shores of streams and lakes, and in "bluffs" (groves of trees on uncultivated land). The species occurrence, density, and survival of coccinellids in most of these overwintering sites have not been studied.

Large numbers of pre-hibernating coccinellids are washed ashore in some years on Manitoba lakes, usually in late August to early October (Lee 1980; Turnock et al. 2003). These beetles usually fly away soon after, to complete their search for hibernating sites, and do not often walk into the adjacent beach-ridge forest. Once, on 1 November 1978, beetles (mainly H. convergens) were washed ashore, but subsequent cold weather forced them to remain near the beach, where few survived the winter (Turnock and Turnock 1979).

In this paper, the density, distribution, species composition, and overwintering survival of coccinellids in the litter under a beach-ridge forest are compared with the density and survival of coccinellids in the litter under a riverbank forest.

\section{Methods}

Beach-Ridge Forest. The abundance and species composition of coccinellids overwintering in the surface litter and soil under a beach-ridge forest on the south shore of Lake Manitoba at the Delta Marsh Field Station (University of Manitoba), $50^{\circ} 11^{\prime} \mathrm{N}, 98^{\circ} 23^{\prime} \mathrm{W}$, about $120 \mathrm{~km}$ WNW of Winnipeg, were recorded. The shore is a sand beach with a forested barrier-beach ridge formed by the reworking of alluvial sand deposits. This beach ridge, about $60 \mathrm{~m}$ wide, supports a mature deciduous forest of Manitoba Maple (Acer negundo L.), Green Ash (Fraxinus pennsylvanica Marsh.), Plains Cottonwood (Populus deltoides Marsh.), and Peachleaf Willow (Salix amagdaloides Anderss.) (Kenkel 1986). The ridge has its highest elevation 5$10 \mathrm{~m}$ from the top of the foreshore and slopes down about $50 \mathrm{~m}$ to the marsh. A road about $10 \mathrm{~m}$ wide along the south edge of the beach ridge separates the forest from the marsh. Samples were taken along five transects, $20 \mathrm{~m}$ apart, perpendicular to the beach. Six samples were taken along each transect at 1, 6, 11, 21, 31, and $41 \mathrm{~m}$ from the top of the foreshore, where the beach ended and the beach-ridge forest began. A sample of the leaf litter and soil above the sandy parent material, $0.25 \mathrm{~m}^{2}$ and $5-10 \mathrm{~cm}$ deep, was collected at each of the 30 locations. Samples were collected after beetle flight had ceased, on 22 October 1992 and 27 October 1993. Each sample was bagged, sorted by 
hand to remove the beetles, and the species and number of coccinellids were recorded.

The numbers and species of coccinellids emerging in the spring were determined from cone traps, each covering a surface area of $0.1028 \mathrm{~m}^{2}$ (Turnock et al. 1987). One trap was set into the litter at each of the 30 locations, near the place where a litter sample had been collected the previous autumn. The traps were set out at each location in late April or May, depending on the disappearance of snow, in 1993, 1994, and 1995. The traps at the apex of the cones were emptied at regular intervals, and the coccinellids identified to species and counted.

Riverbank Forest. The overwintering of coccinellids in a remnant grove of riverbank forest along the Red River at the University of Manitoba, Winnipeg, Manitoba, was determined from records of the insects found in litter samples and emergence traps used to study the overwintering of flea beetles (Chrysomelidae) (Turnock et al. 1987). The grove of trees, about 1.3 ha in area, included Bur Oak (Quercus macrocarpa Michx.), American Elm (Ulmus americana), Manitoba Maple, Green Ash, Black Ash (Fraxinus nigra Marsh.), and Basswood (Tilia americana L.). In this grove, 50 litter samples, each $0.25 \mathrm{~m}^{2},<10 \mathrm{~cm}$ deep, were collected in the autumn of the years 1980-1982, and in the springs of 1980, 1981, and 1983. The samples were taken at $10 \mathrm{~m}$ intervals along five transects running north to south through the grove. Spring emergence was sampled by 100 cone traps, each covering $0.1028 \mathrm{~m}^{2}$, in 1980 and 1981. Two traps were located at $10 \mathrm{~m}$ intervals along each transect, one on each side of the site of a litter sample, as described by Turnock et al. (1987). For coccinellids, only the total number collected in each sampling period was recorded, except in the litter samples of 3 November 1982, where the species were identified but their numbers were not recorded.

\section{Results}

Beach-Ridge Forest. The dominant species in all collections were $H$. tredecimpunctata, $C$. septempunctata, and Coccinella transversoguttata. In the autumn litter samples in $1992(\mathrm{n}=653)$ and $1993(\mathrm{n}=918)$ coccinellid relative abundances were: $0.54 / 0.54(H$. tredecimpunctata); 0.36/0.37 (C. septempunctata); 0.08/ 0.07 (C. transversoguttata); 0.01/0.02 H. convergens; and $0.004 / 0.001 \mathrm{H}$. parenthesis (Say). In the spring emergence samples, the relative abundances of each species in 1993/94/95 were: $H$. tredecimpunctata 0.95/0.78/0.92; C. septempunctata - 0.04/0.19/0.06; and $C$. transversoguttata $-0.02 / 0 / 0$. Neither $H$. convergens nor $H$. parenthesis were found in the spring samples. The distribution of numbers per sample of $H$. tredecimpunctata and C. septempunctata was skewed in both the autumn litter samples and the spring emergence samples, with most samples containing 0,1 , or 2 beetles (Figure 1).
The mean density per $\mathrm{m}^{2}$ of coccinellids in the autumn was 87.1 in 1992 and 122.4 in 1993, and 8.5 and 11.7 in the following springs. The density of coccinellids in the autumn was generally higher on the margins of the forest, but it varied among species (Figure 2). The numbers of $H$. tredecimpunctata were highest near the beach margin in 1993, but they were higher near the marsh margin in 1992. The density of both $C$. septempunctata and $C$. transversoguttata was higher near the beach margin in both years, with only a slight increase along the marsh margin. These patterns suggest that most of the C. septempunctata and $C$. transversoguttata found in the litter near the beach were from aggregations that had washed ashore (Turnock et al. 2003). Hippodamia tredecimpunctata seems mainly to have come from the beach in 1993, but in 1992 more appeared to have come across the marsh to the edge of the forest.

The proportion of living beetles in the autumn litter samples differed little between years, $81.3 \%$ in 1992 $(\mathrm{n}=653)$ and $81.4 \%(\mathrm{n}=913)$ in 1993 (Table 1). The mean proportion of living beetles, by species for both years, was: $H$. tredecimpunctata $=0.963(\mathrm{n}=847)$; C. septempunctata $=0.729(\mathrm{n}=575) ;$ C. transversoguttata $=0.250(\mathrm{n}=116) ; H$. convergens $=0.458(\mathrm{n}=24) ;$ and $H$. parenthesis $=0.500(\mathrm{n}=4)$. Survival of all species was lowest adjacent to the beach and increased toward the edge of the marsh (Figure 3). The decreased survival in the forest edge near the beach was probably caused by the burial of overwintering beetles by sand blown off the beach by strong winds.

Coccinellids emerged from the leaf litter during May and early June in traps throughout the beach-ridge. Most of the beetles $(98 \%, \mathrm{n}=187)$ were of two species, $H$. tredecimpunctata and $C$. septempunctata. The mean density per $\mathrm{m}^{2}$ of emerging coccinellids in 1993 to 1995 was: $17.5,9.1,27.9$ for $H$. tredecimpunctata; 0.65, 2.3, 1.9 for $C$. septempunctata; and $0.32,0,0$ for C. transversoguttata. The pattern of higher densities near the margins of the forest was less prominent in the spring than in the autumn (Figures 2 and 4). The density of emerging beetles was $<20$ per $\mathrm{m}^{2}$ except at distances from the beach of $1 \mathrm{~m}$ in 1995, $31 \mathrm{~m}$ in 1994, and $41 \mathrm{~m}$ in 1993.

The mean overwintering survival (density spring/ density autumn) in the beach-ridge forest for $\mathrm{H}$. tredecimpunctata was 0.370 in the winter of 1992-1993, and 0.139 for 1993-1994 (Table 1). The survival ratios over the same two winters for $C$. septempunctata were 0.021 and 0.051 , and for all coccinellids, 0.212 and 0.096 . The survival of $H$. tredecimpunctata was quite variable with position within the forest (Figure 5). Overwintering survival of all species was very low at $1 \mathrm{~m}$ from the beach margin of the forest, where drifting sand often covered the leaf litter. However, the overwintering survival did not significantly differ among years, density of coccinellids in the autumn, or distance 

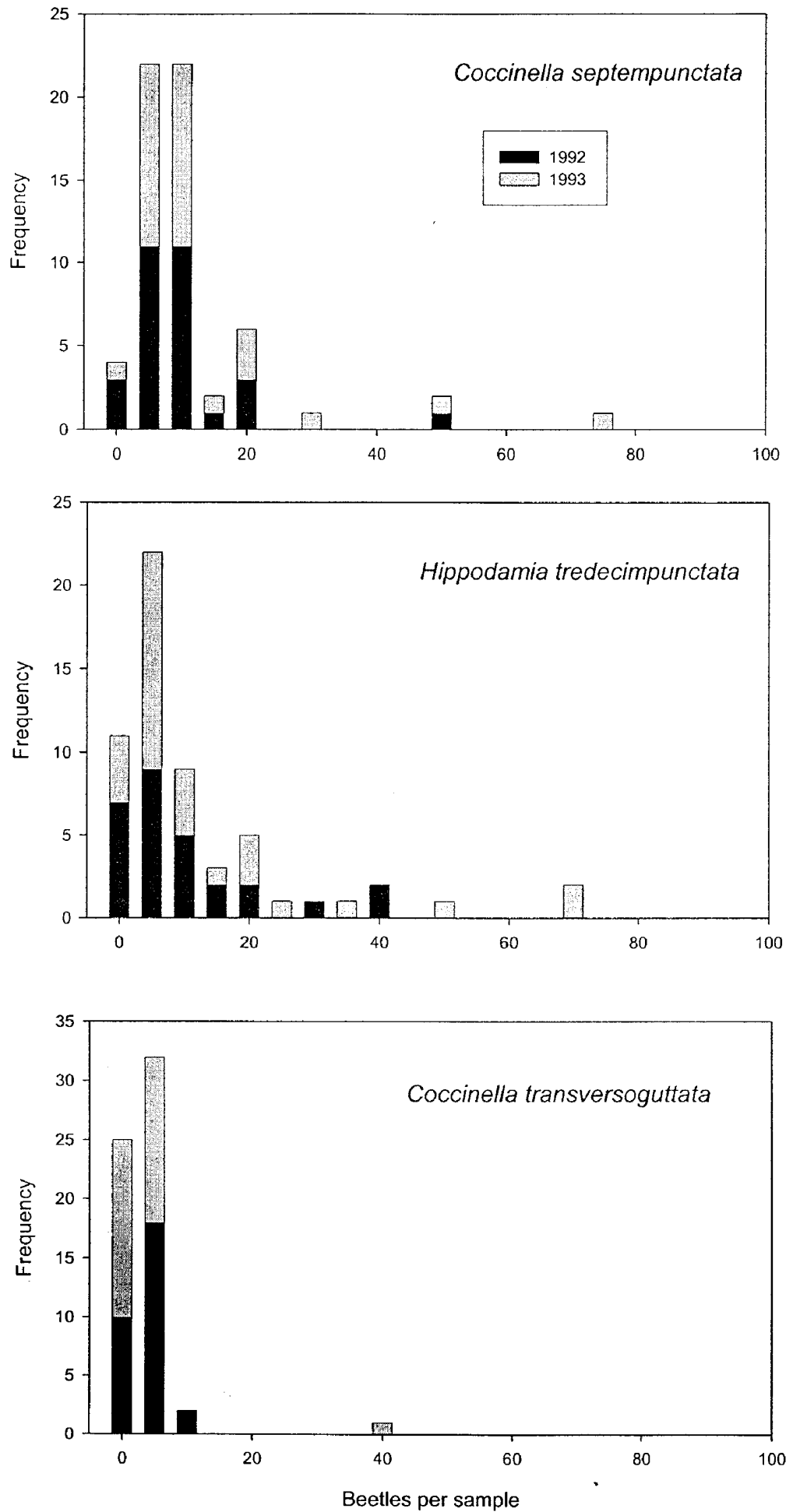

FIGURE 1. Frequency distribution of numbers of coccinellids, Hippodamia tredecimpunctata, Coccinella septempunctata, and Coccinella transversoguttata, per sample of litter $\left(0.25 \mathrm{~m}^{2} \times 5-10 \mathrm{~cm}\right.$ deep $)$ from the floor of the beach-ridge forest at the Delta Marsh Field Station, Manitoba, in late October of 1992 and 1993. $n=60$ for each species. 
TABLE 1. The mean numbers $(\mathrm{N})$ per $\mathrm{m}^{2}$ in autumn litter samples and spring emergence samples, the proportion of living beetles in the autumn samples, and the overwintering survival (density spring emergents/density in autumn), for Coccinella septempunctata (C7), Hippodamia tredecimpunctata (H13), C. transversoguttata (CT), H. convergens (HC), and H. parenthesis $(H P)$, and all coccinellids in the beach-ridge forest at the Delta Marsh Field Station.

\begin{tabular}{|c|c|c|c|c|c|c|}
\hline Species & & 1992 & 1993 & 1993 & 1994 & 1995 \\
\hline \multirow[t]{3}{*}{ H13 } & $\mathrm{N} / \mathrm{m}^{2}$ & 47.3 & 17.5 & 65.6 & 9.1 & 27.9 \\
\hline & Survival & 0.95 & 0.37 & 0.97 & 0.14 & - \\
\hline & $\mathrm{N}$ & 355 & 54 & 492 & 28 & 86 \\
\hline \multirow[t]{3}{*}{$\mathrm{C} 7$} & $\mathrm{~N} / \mathrm{m}^{2}$ & 31.3 & 0.65 & 45.3 & 2.3 & 1.9 \\
\hline & Survival & 0.72 & 0.02 & 0.73 & 0.05 & - \\
\hline & $\mathrm{N}$ & 235 & 2 & 340 & 7 & 6 \\
\hline \multirow[t]{3}{*}{$\mathrm{CT}$} & $\mathrm{N} / \mathrm{m}^{2}$ & 6.9 & 0.32 & 8.5 & 0 & 0 \\
\hline & Survival & 0.37 & 0.05 & 0.16 & 0 & - \\
\hline & $\mathrm{N}$ & 52 & 1 & 64 & 0 & 0 \\
\hline \multirow[t]{3}{*}{$\mathrm{HC}$} & $\mathrm{N} / \mathrm{m}^{2}$ & 101 & 0 & 2.1 & 0 & 0 \\
\hline & Survival & 0.38 & 0 & 0.5 & 0 & - \\
\hline & $\mathrm{N}$ & 8 & 0 & 16 & 0 & 0 \\
\hline \multirow[t]{3}{*}{ HP } & $\mathrm{N} / \mathrm{m}^{2}$ & 0.4 & 0 & 0.13 & 0 & 0 \\
\hline & Survival & 0.67 & 0 & 1 & 0 & - \\
\hline & $\mathrm{N}$ & 3 & 0 & 1 & 0 & 0 \\
\hline \multirow[t]{3}{*}{ All } & $\mathrm{N} / \mathrm{m}^{2}$ & 87.1 & 18.5 & 122.4 & 11.7 & 30.5 \\
\hline & Survival & 0.81 & 0.21 & 0.81 & 0.1 & - \\
\hline & $\mathrm{N}$ & 653 & 57 & 913 & $36^{*}$ & $94 *$ \\
\hline
\end{tabular}

*Includes one specimen of Anistosticta bitriangularis in 1994 and two specimens of Calvia quatuordecimguttata in 1995.

from the beach (analysis of variance, proc glm, SAS Inst. Inc. <www.sas.com>). The high survival of $H$. tredecimpunctata at several locations likely reflects the placing of the emergence traps over local aggregations of beetles in the litter, as does a single record of high survival of $C$. septempunctata.

Riverbank Forest. The litter samples collected on 3 November 1982 contained nine species of coccinellids: Stethorus punctum (LeConte), Scymnus (Pullus) brullei Muls., Hyperaspis benedetti (Say), Chilocorus stigma Say, H. tredecimpunctata, Anatis labiculata (Say), Adalia bipunctata L., C. transversoguttata, and Psyllobora virginimaculata (Say). The mean density of all coccinellid species in the autumn litter collections of 1980-1982 $(\mathrm{n}=110)$ was 2.9 per $\mathrm{m}^{2}(2.0$ $4.3)$, vs. 4.4 (1.5-10.4) in the spring litter collections ( $\mathrm{n}=172$ ) of 1980,1981 , and 1983. Overwintering survival, calculated by dividing the number of living beetles in the spring litter samples by the total number of beetles in the autumn samples, was $76 \%$ for the winter of 1980-1981 and 43\% for the winter of 19821983. Survival during the winter of 1980-1981 was lower, $49 \%$, when the spring density, 0.97 per $\mathrm{m}^{2}$, was based on captures in the emergence traps $(n=10)$.

\section{Discussion and Conclusions}

The studies of coccinellid density and survival in three overwintering sites in southern Manitoba differ in location, years, and sampling design. However, the results of some comparisons may be helpful to future investigators of site selection and survival by overwin- tering coccinellids. In the autumn, more overwintering lady beetles were found in a beach-ridge forest on the shores of Lake Manitoba in 1992 and 1993 than in a riverbank forest in Winnipeg in 1980 to 1981 . The difference in the density between the two sites may have been related to differences in the populations of lady beetles in the years sampled. Another factor could be the availability of overwintering sites in the two areas. The beach-ridge forest was located in an intensivelyfarmed area with few treed areas, whereas the riverbank forest was near suburban Winnipeg, where trees were more abundant. Beetles washed ashore on the beach contributed to the number overwintering in the beach-ridge forest in 1993, but in 1992 more beetles seem to have entered the forest from the side away from the beach.

The beach-ridge forest, despite higher initial densities, had fewer species and fewer beetles emerging in the spring than in the riverbank forest, because of lower overwintering survival. Overwintering survival by beetles may be related to their need for moisture (Hodek and Honěk 1996). The litter under the riverbank forest was thicker and lay upon a clay soil, thus providing a moister environment than the thinner litter on a sandy soil under the beach-ridge forest.

The limited sampling by Turnock and Turnock (1979) on the shores of Lake Manitoba, following a very late flight (1 November) and aggregation of beetles, indicated few beetles survived the winter $(2 \%$ of 1002 per $\mathrm{m}^{2}$ trapped in the beach debris). Even this level of survival is surprising, because beach debris usually is pounded and buried by high water, large 

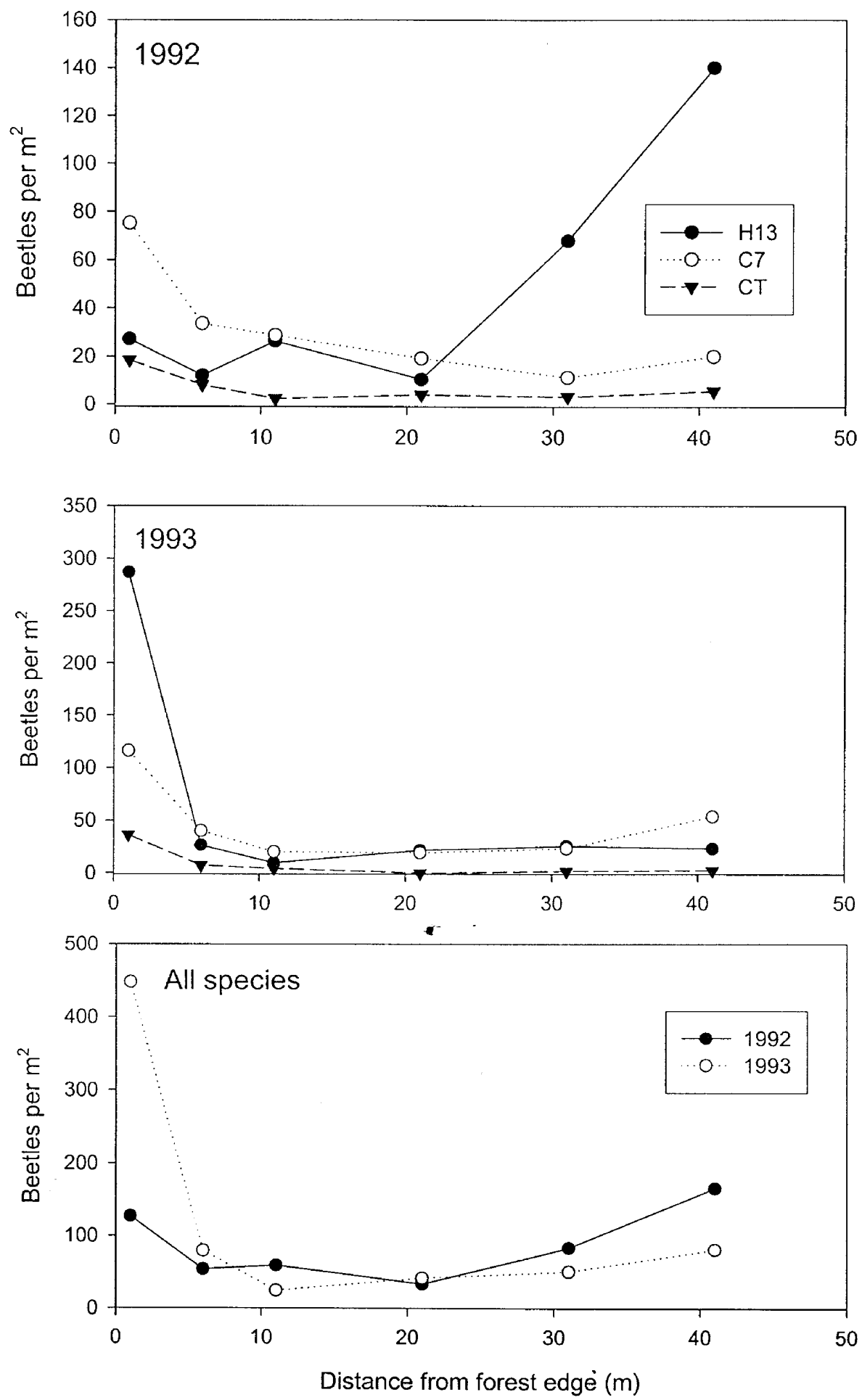

FIGURE 2. Mean density per $\mathrm{m}^{2}$ of Hippodamia tredecimpunctata, Coccinella septempunctata, Coccinella transversoguttata, and all coccinellids, in forest litter samples collected at various distances from the forest edge next to the beach in late October 1992 and 1993 at the Delta Marsh Field Station. 

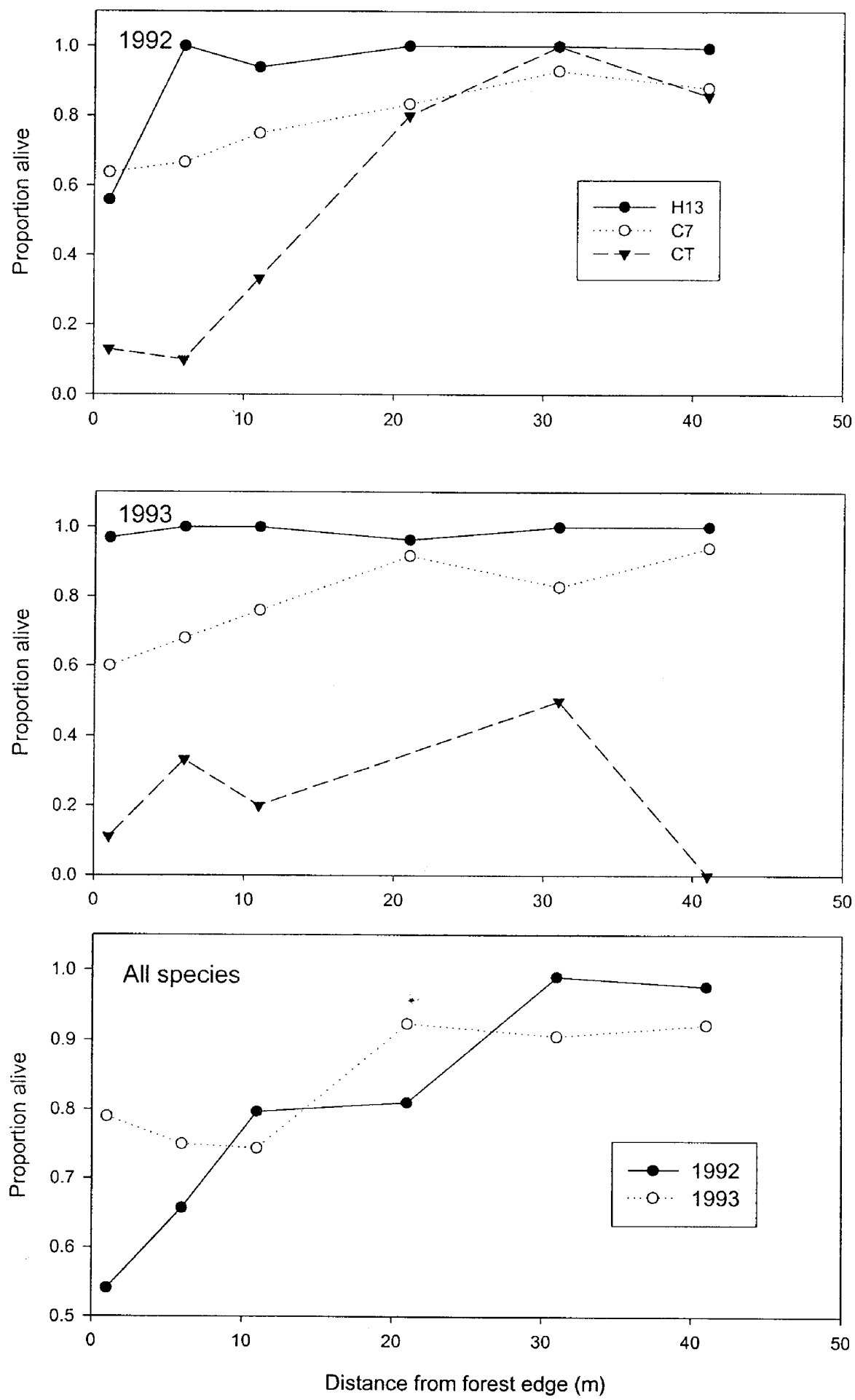

FIGURE 3. Proportion of live individuals of Hippodamia tredecimpunctata (H13), Coccinella septempunctata (C7), Coccinella transversoguttata (CT), and all coccinellids, in litter samples taken at different distances from forest edge next to the beach in late October of 1992 and 1993. 

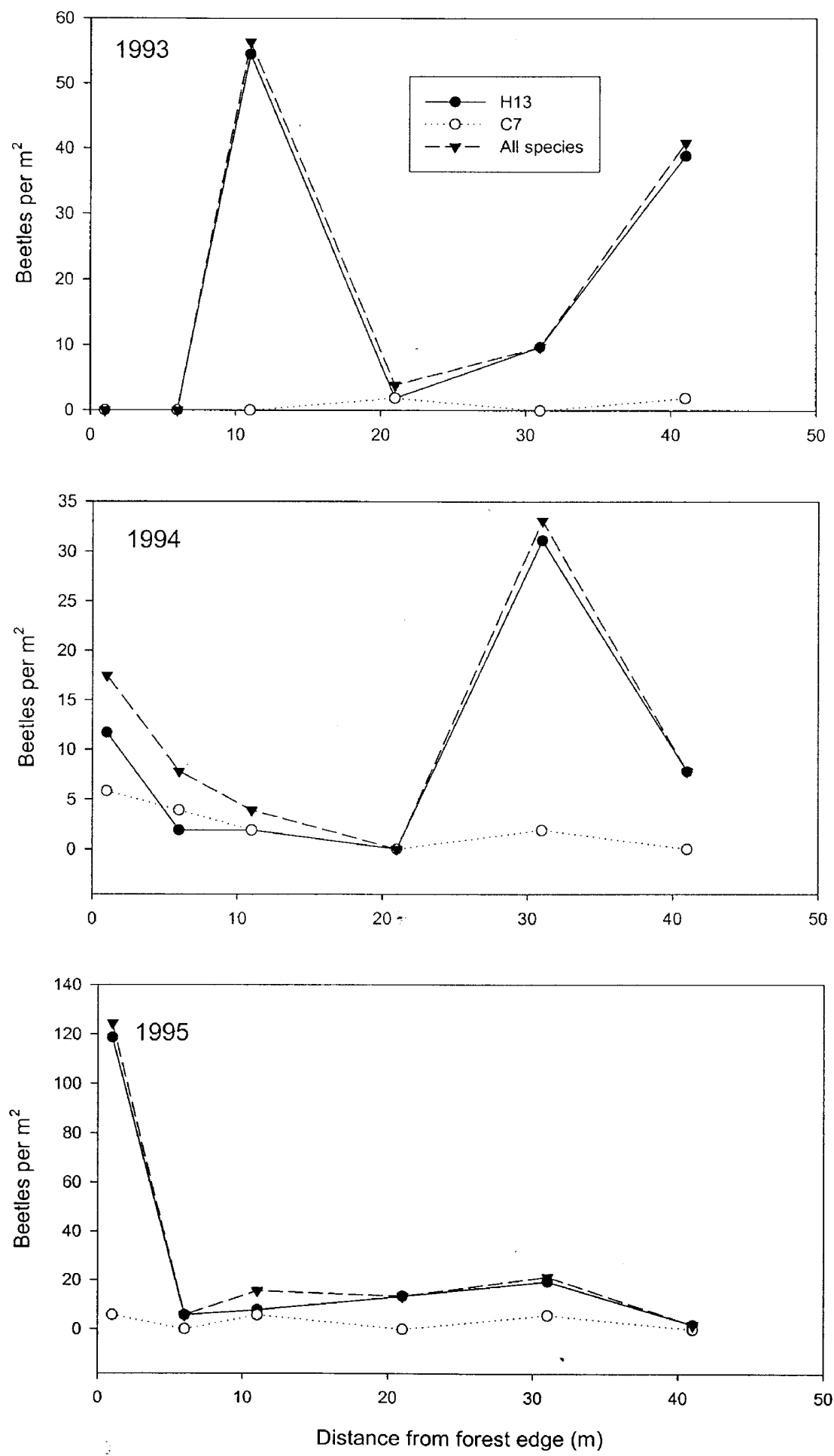

FIGURE 4. Mean density per $\mathrm{m}^{2}$ of Hippodamia tredecimpunctata (H13), Coccinella septempunctata (C7), and all coccinellids, in emergence trap samples collected at different distances from the forest edge next to the beach. The samples were collected from emergence cones placed over the litter in May of 1993, 1994, and 1995. 


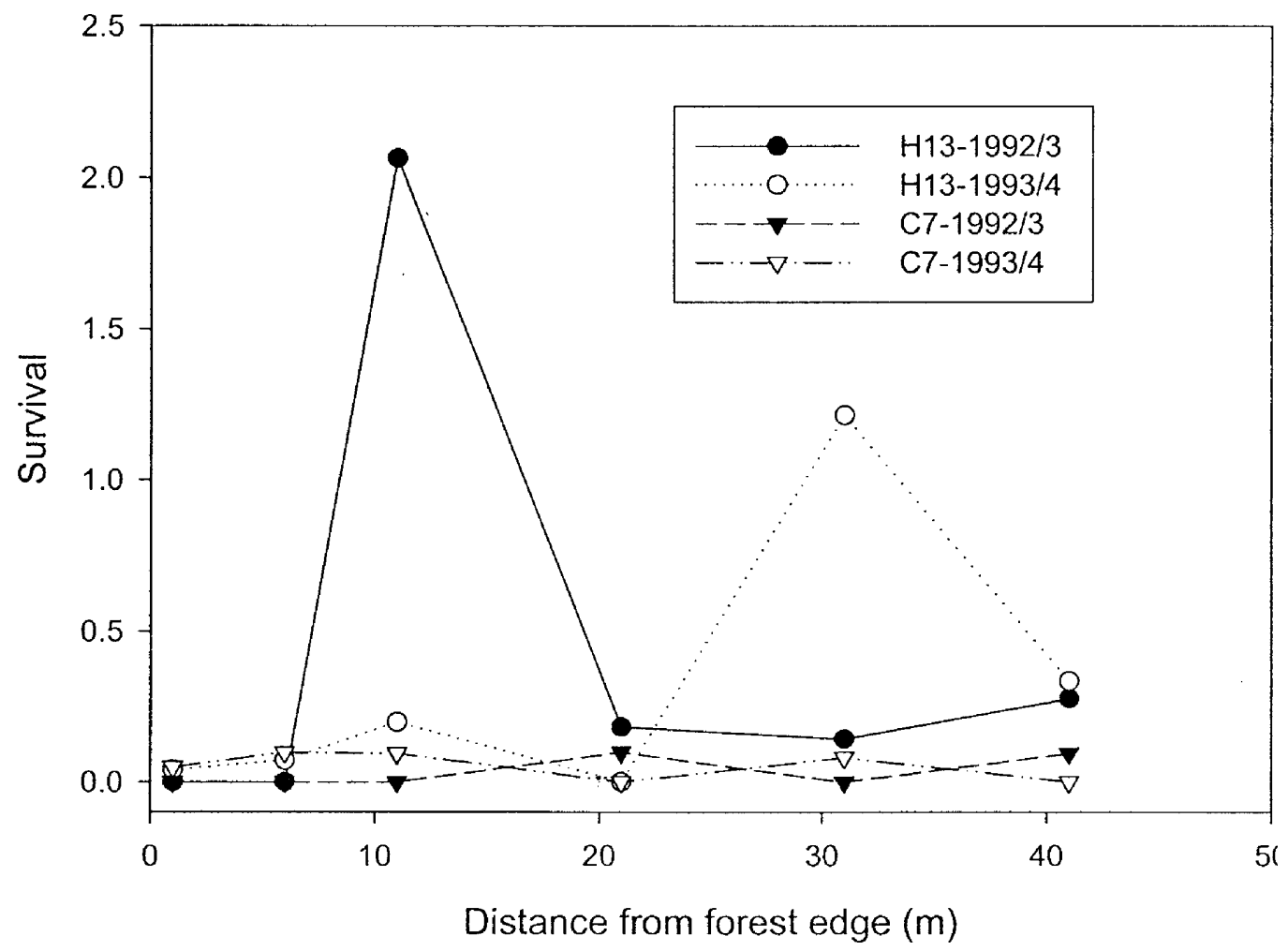

FIGURE 5. Mean overwintering survival ratios for Hippodamia tredecimpunctata (H13), and Coccinella septempunctata (C7), for the winters of 1992-1993 and 1993-1994 in forest litter on the beach ridge at different distances from the forest edge next to the beach at the Delta Marsh Field Station.

waves, and ice chunks from violent autumn and spring storms. In this study the top of the foreshore, where a covering of aspen leaves had accumulated on the sand, had 74 beetles per $\mathrm{m}^{2}$ and overwintering survival was $53 \%$. This location is not likely to be a suitable overwintering site in most years because of high water and waves. The grassy backshore, with little litter, had 28 beetles per $\mathrm{m}^{2}$, of which $18 \%$ survived the winter. The foreshore of the sandy beaches and even the shallow litter in the sparse beach-ridge forest of Trembling Aspen, Populus tremuloides Michx., do not appear to be selected by coccinellids for overwintering. Exceptions can occur when beetles washed ashore after unusually late autumn flights aggregate on the beach when subsequent temperatures are too cool to allow flight, but warm enough to allow limited walking up the beach to the backshore. In these cases the beach-ridge forest, even if unsuitable, is mainly a "last-chance" overwintering site for these beetles.

Four species of coccinellids, $H$. tredecimpunctata, C. septempunctata, C. transversoguttata, and H. convergens (in order of relative abundance) were found in both years in autumn litter samples in the beach- ridge forest, but only the first two species were found in the spring emergence samples in all three years. More $H$. tredecimpunctata (14 and 38\%) survived over winter than C. septempunctata (3 and 5\%) or C. transversoguttata (5 and 0\%). This level of survival of $C$. septempunctata is much lower than the $97 \%$ survival of $C$. septempunctata that had been covered with litter in experimental cages at Edmonton, Alberta (Ryan and Acorn 1999).

Although in Europe C. septempunctata does not migrate long distances to hibernate (Hodek 1960), large flights of this species occur in both autumn and spring, as shown by the numbers of this species that are found in the aggregations washed ashore on the shores of the lakes (Turnock et al. 2003).

Southern Manitoba is mostly cultivated and has a flat terrain, so potential overwintering sites are limited to leaf litter under trees. These habitats probably are both attractive and suitable for the hibernation of coccinellids, but without information on the preferred overwintering sites in this area, the true level of overwintering survival by native and introduced species cannot be compared. 


\section{Acknowledgments}

The statistical advice by S. Woods, technical assistance of R. J. Bilodeau, and the help given by the staff of the Delta Marsh Field Station (University of Manitoba) in providing facilities is gratefully acknowledged. This is Publication Number 305 from the Delta Marsh Field Station (University of Manitoba).

\section{Literature Cited}

Hodek, I. 1960. Hibernation-bionomics in Coccinellidae. Acta Societis Entomolicae Cechosloveniae 57(1): 14-17. [In Czech with English "Discussion and Conclusions"].

Hodek, I., and A. Honěk. 1996. Ecology of Coccinellidae. Series Entomological. Volume 54. Kluwer Academic Publishers. Dordrecht. 464 pages.

Kenkel, N. C. 1986. Vegetation structure and dynamics of the barrier-beach ridge at Delta, Lake Manitoba. Annual Report of the University of Manitoba Delta Marsh Field Station 21: 61-83.
Lee, R. E. 1980. Aggregations of lady beetles on the shores of lakes. American Midland Naturalist 104: 295-304.

Ryan, S. E., and J. H. Acorn. 1999. Overwintering survival of the seven-spot ladybug (Coccinella septempunctata) in Edmonton. Blue Jay 57: 97-100.

Turnock, W. J., and R. W. Turnock. 1979. Aggregations of lady beetles (Coleoptera: Coccinellidae) on the shores of Lake Manitoba. Manitoba Entomologist 13: 21-22.

Turnock, W. J., R. J. Lamb, and R. J. Bilodeau. 1987. Abundance, winter survival, and spring emergence of flea beetles (Coleoptera: Chrysomelidae) in a Manitoba grove. The Canadian Entomologist 119: 419-426.

Turnock, W. J., I. L. Wise, and F. O. Matheson. 2003. Abundance of native coccinellines (Coleoptera: Coccinellidae) before and after the appearance of Coccinella septempunctata. The Canadian Entomologist 135: 391-404.

Received 9 August 2002

Accepted 24 December 2004 